\title{
Article
}

\section{Initiating technical refinements in high- level golfers: Evidence for contradictory procedures}

Carson, H.J., Collins, D., and Richards, J.

Available at http://clok.uclan.ac.uk/12386/

Carson, H.J. ORCID: 0000-0002-3785-606X, Collins, D., ORCID: 0000-00027601-0454 and Richards, J. (2016) Initiating technical refinements in highlevel golfers: Evidence for contradictory procedures. European Journal of Sport Science, 16 (4). pp. 473-482. ISSN 1746-1391

It is advisable to refer to the publisher's version if you intend to cite from the work.

For more information about UCLan's research in this area go to http://www.uclan.ac.uk/researchgroups/ and search for <name of research Group>.

For information about Research generally at UCLan please go to http://www.uclan.ac.uk/research/

All outputs in CLoK are protected by Intellectual Property Rights law, including Copyright law. Copyright, IPR and Moral Rights for the works on this site are retained by the individual authors and/or other copyright owners. Terms and conditions for use of this material are defined in the policies page.

\section{CLoK}

Central Lancashire online Knowledge www.clok.uclan.ac.uk

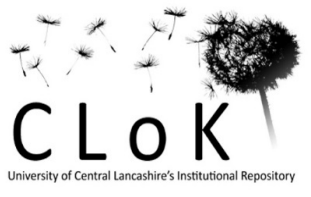


This is a manuscript, as accepted for publication, of an article published by Taylor \& Francis in European Journal of Sport Science on $1^{\text {st }}$ October 2015, available online: http://dx.doi.org/10.1080/17461391.2015.1092586

PLEASE REFER TO THE PUBLISHED VERSION FOR CITING PURPOSES

Initiating Technical Refinements in High-Level Golfers: Evidence for Contradictory Procedures

Howie J. Carson ${ }^{1 *}$, Dave Collins ${ }^{1}$, and Jim Richards ${ }^{2}$

${ }^{1}$ Institute for Coaching and Performance, University of Central Lancashire, Preston UK

${ }^{2}$ Allied Health Research Unit, University of Central Lancashire, Preston UK

*Correspondence concerning this article should be addressed to Howie J. Carson, Institute for Coaching and Performance, University of Central Lancashire, Preston, PR1 2HE. E-mail: HCarson1@uclan.ac.uk 


\begin{abstract}
When developing motor skills there are several outcomes available to an athlete depending on their skill status and needs. Whereas skill acquisition and performance literature is abundant, an under-researched outcome relates to the refinement of already acquired and well-established skills. Contrary to current recommendations for athletes to employ an external focus of attention and a representative practice design, Carson and Collins' (2011) Five-A Model requires an initial narrowed internal focus on the technical aspect needing refinement: the implication being that environments which limit external sources of information would be beneficial to achieving this task. Therefore, the purpose of this paper was to 1) provide a literature-based explanation for why techniques counter to current recommendations may be (temporarily) appropriate within the skill refinement process and, 2) provide empirical evidence for such efficacy. Kinematic data and self-perception reports are provided from high-level golfers attempting to consciously initiate technical refinements while executing shots onto a driving range and into a close proximity net (i.e., with limited knowledge of results). It was hypothesised that greater control over intended refinements would occur when environmental stimuli were reduced in the most unrepresentative practice condition (i.e., hitting into a net). Results confirmed this, as evidenced by reduced intraindividual movement variability for all participants' individual refinements, despite little or no difference in mental effort reported. This research offers coaches guidance when working with performers who may find conscious recall difficult during the skill refinement process.
\end{abstract}

Keywords: coaching, constraints, the Five-A Model, focus of attention, intraindividual movement variability, technical change. 
Initiating Technical Refinements in High-Level Golfers: Evidence for Contradictory Procedures

When developing motor skills there are several outcomes available depending on the athlete's skill status and needs. Undoubtedly the most researched of these are skill acquisition, when co-ordination and control are improved and then established with highlevel automaticity (e.g., Schmidt \& Bjork, 1992; Sigrist, Rauter, Riener, \& Wolf, 2013) and, optimising the performance of an acquired skill by exploiting the automaticity associated with it; for instance, when executing under conditions of high-competitive pressure (e.g., MacPherson, Collins, \& Morriss, 2008; Mesagno \& Mullane-Grant, 2010). In contrast, an under-researched outcome relates to refining (i.e., making a small tweak/polish) already acquired and well-established skills (Carson \& Collins, 2011). Addressing this goal from a systematic perspective, Carson and Collins (2011) proposed the interdisciplinary and nonlinear Five-A Model to enable long-term permanent and pressure-resistant skill refinement. Central to its' mechanistic underpinnings is the requirement for an initial conscious de-automation of the technical aspect requiring refinement (hereafter termed the 'target variable') within the Awareness stage. ${ }^{1}$ However, in seeking empirical evidence to inform optimal practice behaviour during this stage, there appears to have been little consideration to date. This is unfortunate since a recent study suggests that high-level coaches and athletes are in need of assistance when implementing refinements, at least within the sport of golf (see Carson, Collins, \& MacNamara, 2013). As such, this paper focuses on optimising the Awareness stage in golf as an exemplar for other self-paced and closed skill sports.

\footnotetext{
${ }^{1}$ Later stages require the athlete to release such conscious control in an attempt to return to a more automatic state.
} 
Reflecting this lack of evidence, consider the comparatively abundant 'focus of attention' and 'practice design' literature. In the former, the clear recommendation is to direct attention away from internal bodily cues; that is, an external focus on the movement effect within the environment (Wulf, 2013). Complementing this strategy, practice design is encouraged to be representative of the actual performance experience; thus the external cues would be reliable and most informative to the organisation of an optimal motor pattern (Davids, 2012). Contrary to such recommendations, however, Carson and Collins' (2011) Five-A Model suggests a narrowed internal focus on the target variable during the early Awareness stage. Presumably, therefore, this process would benefit by reducing the potential for attention towards external informational sources. According to current applied golf practice solutions, this could be achieved by use of a close proximity net instead of the more commonly employed driving range or golf course practice conditions (Guadagnoli \& Bertram, 2014). Practice design in this situation would, therefore, be most unrepresentative. A non-transparent net eliminates environmental information pertaining to the required shot distance, final ball location and peak trajectory; these factors must be entirely selfdetermined. Therefore, the purpose of this paper was to 1) provide a literature-based explanation for why techniques counter to current recommendations may be (temporarily) appropriate within the process of skill refinement and, 2) provide empirical evidence for such efficacy.

\section{Part 1: Literature-based Explanation}

Although conscious de-automation may seem counterintuitive to enhancing skill, several researchers have supported this procedure. For example, Oudejans, Koedijker, and Beek (2007) suggest that "in reshaping the imperfect automatisms it seems initially necessary to intentionally deautomatize movement control" (p. 41). Referring to the allocation of attention, Beilock, Carr, MacMahon, and Starkes (2002) recommend that when a performer is 
not aiming to "maximize real-time performance but instead to explicitly alter or change performance processes to achieve a different outcome, skill-focused attention may be beneficial" (p.14). Crucially, if an athlete cannot generate and distinguish an alternative movement possibility (e.g., Collins, Morriss, \& Trower, 1999; Hanin, Korjus, Jouste, \& Baxter, 2002), the most likely short-term outcome is a regression back to the original, individually preferred and consistent kinematics (see MacPherson, Turner, \& Collins, 2007) which may represent the antithesis of the desired target variable. Such a characteristic of well-established skills is beneficial during unintentional perturbations; for instance, executing a golf shot from an incline whereby the skill rapidly returns to a most consistent version upon removal of these temporary conditions. It is, however, problematic in the context of implementing long-term permanent and pressure-resistant refinement.

Mechanistically, regressions originate from the existing memory trace's strength/depth of attractor well (Bjork \& Bjork, 1992; Zanone \& Kelso, 1992) being higher/deeper relative to the intended new version and, therefore, more resistant to change (Carson \& Collins, 2015). According to Carson and Collins (2011), the generation and distinction of a new movement possibility serves to initiate a process of being able to inhibit the original skill and activate that of the desired. This process would not be possible if control over the existing whole skill remained unchanged; kinematics would continue to persist. De-automation, therefore, represents a purposeful, nay essential but temporary, regression in motor control (Christina \& Corcos, 1988). Accordingly, practice conditions that can promote high levels of conscious awareness best enable (although do not guarantee, since this is dependent on successful completion of previous and subsequent Five-A Model stages) long-term permanence of the new version of skill through the distinction it provides (Bar-Eli, 1991). 
In considering the research of Glenberg, Schroeder, and Robertson (1998), executing golf shots into a net should be an obvious procedure for achieving de-automation. Indeed, detaching oneself from external surroundings is a natural strategy employed when the intended goal requires high levels of reflection. As these authors explain, "the cognitive system is normally 'clamped' to the environment. That is, environmental constraints on action normally control conceptualization" (p. 651). However, in situations that require difficult reflective activity (e.g., remembering an old phone number or taking a quiz) we naturally avert our gaze; that is, "we close our eyes or look at the sky to suppress the environment's control over cognition" (p. 651) ${ }^{2}$. Indeed, Glenberg et al. (1998) showed this behaviour to be consistent, functional and causally linked to better memory performance, with the frequency correlated with task difficulty. Phelps, Doherty-Sneddon, and Warnock (2006) further explain that gaze aversion reflects "the need to concentrate on drawing information from memory and/or engage in on-line cognitive processing" (p. 577). In short, by removing distracting stimuli, attention is more effectively focused internally towards the cognitive task. Thus, within the Awareness stage, reducing the availability of visual information increases the reliability and, therefore relative weighting, of information that can be gained from kinaesthesia (Ernst \& Banks, 2002); a factor that has already been identified as important to the awareness process (Carson, Collins, \& Richards, 2014a). Accordingly, following the Five-A Model's 'Analysis stage,' executing into a net could temporarily 'unclamp' the cognitive system from the environment (Glenberg et al., 1998) and enable improved access to motor response propositions within memory.

Within an observational learning study by Horn, Williams, Scott, and Hodges (2005), an aversion strategy was shown to be effective for drawing attention to kinematic features of

\footnotetext{
${ }^{2}$ We wish to explicitly avoid any link here to neuro linguistic programming (Grinder \& Bandler, 1976); in this particular context the specific gaze direction is irrelevant, only that the gaze is directed away from distracting environmental stimuli.
} 
a motor skill. Specifically, Horn et al. compared video, point-light demonstration and control groups when executing soccer chip shots without knowledge of results (KR). Findings showed participants' visual search patterns to have fewer fixations and for longer duration on the model's kinematics when observing a point-light versus video display; when presented with less information, visual search was directed to fewer items of information. Crucially, however, kinematics in both modelling groups imitated those of the model with immediate effect, whereas, this has not been shown to be the case in previous studies that included KR (e.g., Horn, Williams, \& Scott, 2002). This indicates, therefore, that removing KR can rapidly increase the saliency of an observed model as the primary source of information. When available, the influence of a model may be diminished due to the constraining effect that KR has on the choice of movement (the cognitive system being clamped to the environment; cf. Glenberg et al., 1998). In short, the athlete does not perceive the required differences as quickly and so imitation is less obvious. Notably, if the demonstration constituted a best attempt self-model (see Carson, Collins, \& Jones, 2014), the most important and meaningful response propositions would be apparent and, therefore, fed forward into future executions (Lang, 1979).

While Horn et al. (2005) were able to limit perceptual information by providing ear plugs (removing auditory outcome feedback) and a head-mounted, polymer-dispersed liquidcrystal screen (removing visual feedback upon ball contact), the use of a practice net represents a more practical solution within applied golf coaching environments. It is acknowledged that some feedback will be obtained from the ball's initial starting direction before impacting with the net (typically $\sim 3 \mathrm{~m}$ away), as well as feedback from the sound at ball contact. Crucially, however, the ability to direct attention towards the target variable without compromising whole-skill execution (i.e., via attentional cueing) is a positive aspect of such method. This is in contrast to other part-practice methods (e.g., fractionation), 
whereby the relative movement of less consciously controlled components (i.e., non-target variables) is not maintained, presenting a potentially negative outcome for high-level performers considering those components' existing level of automaticity and effectiveness. While coaches might implement slow motion or static positioning drills (e.g., Toner, Nelson, Potrac, Gilbourne, \& Marshall, 2012), we speculate that this is a heuristic response to experienced performers' difficulty in regaining conscious control over usually wellautomated target variables. As such, the performance of interest should be the full execution and not a drill; when possible, execution should be whole (Carson, Collins, \& Jones, 2014; Hanin et al., 2002).

\section{Measuring Conscious Control in Applied Environments: Intra-individual Movement Variability}

Recent indexes of relative awareness state in high-level performers have been demonstrated using intra-individual movement variability. Carson, Collins, et al. (2014a) showed support for the proposal that inter-trial kinematic variability of target variables reduce when consciously controlled to intentionally make a refinement. In a study of PGA Professional golfers, 10 executions representing an individually preferred (i.e., natural) golf shot (specified by shape of ball flight) were compared to 10 non-preferred shots (i.e., the opposite shape of ball flight to the preferred condition). Under the non-preferred condition, participants identified and reported a single kinaesthetic cue that would modify their technique to achieve the desired ball flight; the aim being to maintain a high level of awareness towards this target variable. Furthermore, participants were regularly reminded (following Trials 3, 6 and 9) to apply increased attention towards their kinaesthetic feel, acting to avert attention away from the performance outcome and environmental information available at a driving range setting (e.g., the distal target). Mental effort scores reported immediately following each condition reflected a notable increase as predicted. Results 
showed reduced variability for the target variables and increased variability for non-target variables; thus representing a desirable imbalance towards absolute motor control. In accordance with notions put forward by the UnControlled Manifold (UCM) approach (see Scholz \& Schöner, 1999), the authors suggested that this nonlinear pattern of change occurred because performers had consciously made one parameter more important, therefore lessening the relative importance across others. Whereas variability levels across kinematics in the preferred ball flight condition could be considered as functional, the patterns produced within the non-preferred condition can be considered as necessarily dysfunctional. Importantly, however, when comparing between conditions, this method has the potential to provide an indication that increased conscious attention is being applied, where attention is being applied to (in combination with self-report) and whether one condition prompts a different level of attention allocated. It is the latter of these that the following research primarily addresses.

\section{Part 2: Empirical Evidence}

The present research formed part of an applied longitudinal study examining individual cases of technical refinement in high-level golfers. Extending the findings from Carson, Collins, et al. (2014a), we were interested in the covariance of kinematic parameters depending on golfers' allocation of attention. Notably, during this work golfers reported greater ease to focus on their intended full swing refinements when executing into a net as opposed to on a driving range. Therefore, the aim of the present research was to determine whether such differences in environmental conditions resulted in lower inter-trial variability for consciously attended target variables. In doing so, our motivation was to assess our thinking and rationalising as scientist-practitioners for a direct link between the theory and practice reviewed above. Indeed, understanding the underpinning theoretical mechanism of 'what needs to be done and why' (declarative knowledge) and 'how to do it' (procedural 
knowledge) has been explained as a crucial factor towards developing expertise across different coaching scenarios and performers (Martindale \& Collins, 2005). Although hitting into a net is not uncommon in golf, verification of effect would seem essential to avoid counterproductive outcomes through incorrect or less than optimum use of the approach.

Accordingly, this study examined executions of high-level golfers in two different practice environments when performing under high-awareness conditions. Due to the clear applied implication desired, practice environments were represented by outdoor executions onto a driving range (termed 'driving range condition') and into a practice net (termed 'net condition') at a golf club setting (i.e., commonly available conditions). There was no control group, each participant acted as their own control; data are therefore presented individually. It was hypothesised that the kinematic variability of target variables would be lower in the net versus driving range condition. Thus, removing potential distractions from the environment would improve the target variables' recall accuracy through heightened kinaesthetic feel (a requirement of participants' current training).

\section{Method}

Participants. Three right-handed male golfers (Participants A-C; $M_{\text {age }}=31.3$ years, $S D=9.3$ ) were recruited for this study. Reflecting their high-skill status, playing ability included a member of The Professional Golfers' Association of Great Britain and Ireland (A), a PGA Europro Tour playing professional (B) and an amateur golfer with a 0 handicap (C). Preceding data collection for the longitudinal study, participants provided informed consent. Ethical approval was granted from the University's Ethics Committee prior to data collection.

Procedure. Following a self-conducted warm-up, participants were fitted with, and then calibrated in, a mobile inertial sensor motion capture suit operating at a sampling rate of $120 \mathrm{~Hz}$ (Xsens MVN Biomech suit, Xsens ${ }^{\circledR}$ Technologies B.V., Netherlands), as described by Carson, Collins, and Richards (2014b). Participants remained wearing the suit for the 
entire test procedure, which consisted of a 10-full swing execution block in a randomly assigned net or driving range condition; followed by another 10 swings to satisfy the alternative condition. All executions were performed from an artificial turf mat using participant's own 7-iron and legally conforming golf balls. In the net condition, participants executed at a distance of approximately $3 \mathrm{~m}$ away from the net, whereas executions on the driving range were made towards a realistically achievable and straight target $137.16 \mathrm{~m}$ (labelled as 150 yards) away. Executions under both conditions were performed without other players present or onlookers nearby. A private teaching room was used in the driving range condition and practice nets were temporarily closed off to other golfers. The use of an artificial turf mat is common under these conditions and ensured a consistent hitting surface. During executions, participants focused on a single movement component (target variable), as per their intended technical refinement. Identically to Carson, Collins, and Richards' (2014a) study, following Trials 3, 6 and 9 of each condition, prompts were provided to maintain attention towards target variables and kinaesthetic feel. These were derived previously as a collaborative process between each participant, their coach and first author. To record the intensity of focus, the Rating Scale for Mental Effort (RSME; Zijlstra, 1993) was employed, as described by Carson, Collins, et al. (2014a).

Data processing and analysis. Raw kinematic data were exported into c $3 \mathrm{~d}$ file format and each body segment was modelled in six degrees-of-freedom with Visual3 $\mathrm{D}^{\mathrm{TM}}$ v4.89.0 software (C-Motion® Inc., Germantown, MD, USA). Data were not filtered at this stage due to the employment of Kalman filtering within the Xsens software (Roetenberg, Luinge, \& Slycke, 2009). To ensure a most direct and therefore meaningful measure of technique, kinematic variables were defined using anatomical segment (as opposed to global) coordinate systems (see Brown, Selbie, \& Wallace, 2013). Employing segment coordinate systems countered the possibility of variability being attributed to inter-trial differences in 
golfers' stance position. Furthermore, following each trial, data were examined for drift of the body segments in the coordinate system and the participants were recalibrated. During this process, little or no drift was observed which would influence the kinematics, although some global drift was noticed. Target variables were discussed with each participant and their coach, defined using conventional golf coaching terminology (e.g., PGA, 2010) and then translated into a three-dimensional segment coordinate system. Accordingly, Participant A attempted a backswing change to his left elbow position in order to modify his connection between the arms and torso movement which is understood to improve both shot distance and direction; this was defined as the distal end of the left humerus relative to the sternum segment centre of mass in the anterior-posterior direction. The backswing was defined by three automatically identified events, 'swing onset' as the frame when the left hand's centre of gravity linear velocity crossed a threshold value of $0.2 \mathrm{~m} / \mathrm{s}$ in the local medial-lateral axis relative to the pelvis, the 'mid-backswing' as the frame when the left hand crossed a threshold of $0.0 \mathrm{~m}$ relative to a predetermined position on the spine (VT12L3) in the local vertical axis on swing ascent and, 'top of swing' as the frame when the right-hand distal end position reached its maximum value in the global vertical axis prior to swing descent. Participants $\mathrm{B}$ and $\mathrm{C}$ attempted changes to target variables during their downswing; Participant B's change related to the swing path which is understood to influence the initial shot direction. This target variable was defined as the left-hand distal end position relative to the right humerus distal end position in the anterior-posterior direction. Participant C's change addressed his lateral movement of the swing centre which was defined as the proximal end of the left humerus relative to the pelvis centre of mass in the medial-lateral direction. For these refinements, the downswing was defined between the top of swing and a 'bottom of swing' event, identified as the frame when the distal end position of the right hand reached its minimum position in the global vertical axis on swing descent. For graphical 
analyses of kinematic and variability data, time between each event was normalised to 101 points. Variability was assessed by the standard deviation across trials of each condition at each point. Positional and variability data were extracted between key events and exported to Microsoft Excel® 2010 for graphical plotting. Due to the individual nature of these data and unknown magnitude of any meaningful differences that might occur, statistical analyses were inappropriate. Instead, analysis was limited to observed differences in kinematic and variability measures on an intra-individual basis (Carson, Collins, et al., 2014a).

\section{Results}

There was little, if any, difference in the perceived amount of mental effort applied when executing under both conditions (inter-individual range $=0-8$ scale points; Figure 1). For variability, however, values were consistently lower in the net compared to the driving range condition for all target variables (Figure 2). Kinematic data, as measured by the mean position for each set of 10 trials, indicate subtle differences in kinematics for Participants A and $\mathrm{C}$, but rather more substantial disparity in Participant B (Figure 3).

\section{Discussion}

This study found inter-trial movement variability differences for targeted refinement variables when executing golf swings in front of a net versus on a driving range, despite retrospective perceptions indicating very similar levels of mental effort. According to gaze aversion research (Glenberg et al., 1998) and the suggestions of Carson, Collins, et al. (2014a), a more consistent kinematic performance can be explained by an improvement in the conscious memory recall of these target variables. Furthermore, these data support those of Horn et al. (2005) in that limiting KR corresponded to more accurate achievement of the intended behaviour. Notably, the study design was able to satisfy requests for levels of automaticity to be expressed in relative terms (Moors \& De Houwer, 2006). In summary, we interpret the findings to indicate that an increased state of intentional control (largely 
kinaesthetic; Wertheim, 1981) over target variables was achieved when attention-competing environmental information was absent. Findings therefore demonstrate support for environmental changes impacting on motor control processes.

On closer inspection of Figure 2, however, it would appear that different strategies, or at least conceptualisations of the individual refinements, were implemented under both conditions. For example, despite Participants B and C attempting downswing changes only, Participant B showed an almost consistent disparity throughout the back and downswings, whereas Participant $\mathrm{C}$ only showed this pattern during the downswing. By comparison, data for Participant A show a distinct reduction in variability for most of the backswing, however with a gradually smaller difference between the two conditions as the top of swing is approached. Such idiosyncrasies may be unique to each individual and/or the specific nature of refinement implemented. Moreover, the finding of little to no difference in mental effort reported may relate to more efficient attentional use, as opposed to the same attentional strategy per se. These findings lend support to the individuality of human nature (see Carson, Collins, et al., 2014b) and the need to investigate the skill refinement on a case study basis.

Interpreting these findings against notions contained within the UCM concept (Scholz \& Schöner, 1999), target variables were assigned greater importance by the central nervous system due to their higher consistency. Indeed, this idea that the target variable must be allocated increased importance is apparent within the stage preceding the Awareness stage, namely Analysis. From a psychosocial perspective, the rationale for making a refinement and the aspect requiring increased attention must be 'sold' to the athlete if one is to expect commitment to a long-term, or indeed any, training intervention. In other words, if the athlete does not perceive the need to focus on their target variable - they do not understand the importance of doing so- this will likely impact negatively on the level of process engagement. As such, the implication for coaches is clear, especially when attempting to de- 
automate the skill and therefore induce a suboptimal level of performance. While much of the limited research into skill refinement has adhered to such recommendations (e.g., Carson, Collins, \& Jones, 2014; Collins et al., 1999; Hanin, Malvela, \& Hanina, 2004), it is not always addressed, or at least when it comes to empirical reporting (cf. Giblin, Farrow, Reid, Ball, \& Abernethy, 2015).

So, in contrast to current recommendations for representative practice environments (e.g., Davids, 2012), findings support the necessity for coaches to consider the intended practice outcome, both on a behavioural and control level (Newell, Liu, \& Mayer-Kress, 2001). Data support the need for KR if practicing to exploit established levels of automaticity; as evidenced by increased levels of variance when executing in the driving range as opposed to net condition. However, in circumstances requiring a deliberate and consciously-induced perturbation (i.e., the Awareness stage), data suggest hitting in front of a net to be more beneficial. As an additional implication, future research assessing the optimisation of golf swing motor control should endeavour to limit testing in nets under laboratory conditions; something that is currently common practice within golf research (e.g., Langdown, Bridge, \& Li, 2013) when this is used to offer a representative picture of participants' (individually specific) stable technique.

From an applied perspective there may be reluctance from coaches and athletes to deautomate technique, due to consequent perceived negative performance outcomes. Reassurance is provided that this is only a temporary state of suboptimal motor control within a nonlinear process (see Carson \& Collins, 2011), but should be considered as absolutely necessary. Focus will inevitably need to change as a feature of progression (Hristovski, Davids, Araújo, \& Button, 2006). Of course, optimal return to competitive performance requires a later submission of control over the target variable and the adoption of a more holistic focus (MacPherson et al., 2008), coupled with a proactive step to internalise the skill 
under conditions of high anxiety. As such, the Awareness stage's timing within the context of a competitive season is important; not least due to the potential negative impact this may have on an athlete's confidence. Indeed, it is for these reasons that coaches should address these potential concerns during the earlier skill acquisition process. Teaching imagery skills and ensuring that an athlete is capable of regulating realistic performance expectations, for instance, is not only useful during times of technical refinement, but act as tools for overcoming performance setbacks and recovery from injury (Collins \& MacNamara, 2012).

When conducting applied research there is always a need to consider the trade-off between ecological validity and measurement accuracy. As such, it is acknowledged that this study is not without limitation in this regard. While the majority of kinematic research has employed optoelectronic camera systems (e.g., Oqus and Vicon), implementation of this equipment is extremely difficult at outdoor golf settings and hence our decision to employ inertial sensor technology. Future research should seek to validate inertial sensor suits (e.g., Xsens) against the reference standard of these camera systems when utilising most current modelling techniques to determine accuracy during specific tasks for kinematics and movement variability.

\section{Conclusion}

We have reported a genuine account of scientist-practitioners' thinking to resolve a decision within the applied context of high-level golf coaching. Theory and empirical findings were reviewed to support the removal of external environmental information during the Five-A Model's Awareness stage. The rationale being underpinned by an enhanced memory recall of a target variable during the movement de-automation process. Furthermore, we presented our rationalisation for employing an objective measure (movement variability) to assess this process. In doing so, hitting into a net demonstrated lower levels of inter-trial variability for target variables. Practically, this research offers 
coaches guidance when working with golfers who might be challenged in generating conscious recall during the Awareness stage (Carson \& Collins, 2011). This study provides extended support for the underpinning principle of gaze aversion (Glenberg et al., 1998) and an appropriate measure to assess between practice environments. Overall, it is hoped that applied sport science support will adopt similar approaches when it comes to exposing their decision-making; therefore ensuring services provided to their clients is grounded in reason and addresses individual performers' needs. 


\section{References}

Bar-Eli, M. (1991). On the use of paradoxical interventions in counseling and coaching in sport. The Sport Psychologist, 5, 61-72.

Beilock, S. L., Carr, T. H., MacMahon, C., \& Starkes, J. L. (2002). When paying attention becomes counterproductive: Impact of divided versus skill-focused attention on novice and experienced performance of sensorimotor skills. Journal of Experimental Psychology: Applied, 8, 6-16. doi: 10.1037/1076-898x.8.1.6

Bjork, R. A., \& Bjork, E. L. (1992). A new theory of disuse and an old theory of stimulus fluctuation. In A. Healy \& R. Shiffrin (Eds.), From learning processes to cognitive processes: Essays in honor of William K. Estes (Vol. 2, pp. 35-67). Hillsdale, NJ: Erlbaum.

Brown, S. J., Selbie, W. S., \& Wallace, E. S. (2013). The X-Factor: An evaluation of common methods used to analyse major inter-segment kinematics during the golf swing. Journal of Sports Sciences, 31, 1156-1163. doi:

$10.1080 / 02640414.2013 .775474$

Carson, H. J., \& Collins, D. (2011). Refining and regaining skills in fixation/diversification stage performers: The Five-A Model. International Review of Sport and Exercise Psychology, 4, 146-167. doi: 10.1080/1750984x.2011.613682

Carson, H. J., \& Collins, D. (2015). The fourth dimension: A motoric perspective on the anxiety-performance relationship. International Review of Sport and Exercise Psychology, Advance online publication. doi: 10.1080/1750984X.2015.1072231

Carson, H. J., Collins, D., \& Jones, B. (2014). A case study of technical change and rehabilitation: Intervention design and interdisciplinary team interaction. International Journal of Sport Psychology, 45, 57-78. doi: 10.7352/IJSP2014.45.057 
Carson, H. J., Collins, D., \& MacNamara, Á. (2013). Systems for technical refinement in experienced performers: The case from expert-level golf. International Journal of Golf Science, 2, 65-85.

Carson, H. J., Collins, D., \& Richards, J. (2014a). Intra-individual movement variability during skill transitions: A useful marker? European Journal of Sport Science, 14, 327-336. doi: 10.1080/17461391.2013.814714

Carson, H. J., Collins, D., \& Richards, J. (2014b). “To hit, or not to hit?” Examining the similarity between practice and real swings in golf. International Journal of Golf Science, 3, 103-118. doi: 10.1123/ijgs.2014-0003

Christina, R. W., \& Corcos, D. M. (1988). Coaches guide to teaching sport skills. Champaign, IL: Human Kinetics.

Collins, D., \& MacNamara, Á. (2012). The rocky road to the top: Why talent needs trauma. Sports Medicine, 42, 907-914. doi: 10.2165/11635140

Collins, D., Morriss, C., \& Trower, J. (1999). Getting it back: A case study of skill recovery in an elite athlete. The Sport Psychologist, 13, 288-298.

Davids, K. (2012). Learning design for nonlinear dynamical movement systems. The Open Sports Science Journal, 5, 9-16. doi: 10.2174/1875399X01205010009

Ernst, M. O., \& Banks, M. S. (2002). Humans integrate visual and haptic information in a statistically optimal fashion. Nature, 415, 429-433. doi: 10.1038/415429a

Giblin, G., Farrow, D., Reid, M., Ball, K., \& Abernethy, B. (2015). Exploring the kinaesthetic sensitivity of skilled performers for implementing movement instructions. Human Movement Science, 41, 76-91. doi: 10.1016/j.humov.2015.02.006 
Glenberg, A. M., Schroeder, J. L., \& Robertson, D. A. (1998). Averting the gaze disengages the environment and facilitates remembering. Memory \& Cognition, 26, 651-658. doi: $10.3758 / \mathrm{BF} 03211385$

Grinder, J., \& Bandler, R. (1976). The structure of magic II. Palo Alto, CA: Science and Behavior Books.

Guadagnoli, M. A., \& Bertram, C. P. (2014). Optimizing practice for performance under pressure. International Journal of Golf Science, 3, 119-127. doi: 10.1123/ijgs.20140021

Hanin, Y., Korjus, T., Jouste, P., \& Baxter, P. (2002). Rapid technique correction using old way/new way: Two case studies with Olympic athletes. The Sport Psychologist, 16, 79-99.

Hanin, Y., Malvela, M., \& Hanina, M. (2004). Rapid correction of start technique in an Olympic-level swimmer: A case study using old way/new way. Journal of Swimming Research, 16, 11-17.

Horn, R. R., Williams, A. M., \& Scott, M. A. (2002). Learning from demonstrations: The role of visual search during observational learning from video and point-light models. Journal of Sports Sciences, 20, 253-269. doi: 10.1080/026404102317284808

Horn, R. R., Williams, A. M., Scott, M. A., \& Hodges, N. J. (2005). Visual search and coordination changes in response to video and point-light demonstrations without KR. Journal of Motor Behavior, 37, 265-274.

Hristovski, R., Davids, K., Araújo, D., \& Button, C. (2006). How boxers decide to punch a target: Emergent behaviour in nonlinear dynamical systems. Journal of Sports Science and Medicine, 5, 60-73.

Lang, P. J. (1979). A bio-informational theory of emotional imagery. Psychophysiology, 16, 495-512. doi: 10.1111/j.1469-8986.1979.tb01511.x 
Langdown, B. L., Bridge, M. W., \& Li, F.-X. (2013). Address position variability in golfers of differing skill level. International Journal of Golf Science, 2, 1-9.

MacPherson, A. C., Collins, D., \& Morriss, C. (2008). Is what you think what you get? Optimizing mental focus for technical performance. The Sport Psychologist, 22, 288303.

MacPherson, A. C., Turner, A. P., \& Collins, D. (2007). An investigation of natural cadence between cyclists and noncyclists. Research Quarterly for Exercise and Sport, 78, 396-400. doi: 10.1080/02701367.2007.10599438

Martindale, A., \& Collins, D. (2005). Professional judgment and decision making: The role of intention for impact. The Sport Psychologist, 19, 303-317.

Mesagno, C., \& Mullane-Grant, T. (2010). A comparison of different pre-performance routines as possible choking interventions. Journal of Applied Sport Psychology, 22, 343-360. doi: 10.1080/10413200.2010.491780

Moors, A., \& De Houwer, J. (2006). Automaticity: A theoretical and conceptual analysis. Psychological Bulletin, 132, 297-326. doi: 10.1037/0033-2909.132.2.297

Newell, K. M., Liu, Y.-T., \& Mayer-Kress, G. (2001). Time scales in motor learning and development. Psychological Review, 108, 57-82. doi: 10.1037/0033-295X.108.1.57

Oudejans, R. R. D., Koedijker, J. M., \& Beek, P. J. (2007). An outside view on Wulf's external focus: Three recommendations. E-journal Bewegung und Training, 1, 41-42. $\underline{\text { www.ejournal-but.de }}$

PGA. (2010). Study guide: Golf coaching 1. United Kingdom: The Professional Golfers' Association Limited.

Phelps, F. G., Doherty-Sneddon, G., \& Warnock, H. (2006). Helping children think: Gaze aversion and teaching. British Journal of Developmental Psychology, 24, 577-588. doi: 10.1348/026151005X49872 
Roetenberg, D., Luinge, H., \& Slycke, P. (2009). Xsens MVN: Full 6DOF human motion tracking using miniature inertial sensors. Technical report. Xsens Technologies B.V.

Schmidt, R. A., \& Bjork, R. A. (1992). New conceptualizations of practice: Common principles in three paradigms suggest new concepts for training. Psychological Science, 3, 207-217. doi: 10.1111/j.1467-9280.1992.tb00029.x

Scholz, J. P., \& Schöner, G. (1999). The uncontrolled manifold concept: Identifying control variables for a functional task. Experimental Brain Research, 126, 289-306. doi: $10.1007 / \mathrm{s} 002210050738$

Sigrist, R., Rauter, G., Riener, R., \& Wolf, P. (2013). Augmented visual, auditory, haptic, and multimodal feedback in motor learning: A review. Psychonomic Bulletin \& Review, 20, 21-53. doi: 10.3758/s13423-012-0333-8

Toner, J., Nelson, L., Potrac, P., Gilbourne, D., \& Marshall, P. (2012). From 'blame' to 'shame' in a coach-athlete relationship in golf: a tale of shared critical reflection and the re-storying of narrative experience. Sports Coaching Review, 1, 67-78. doi: $10.1080 / 21640629.2012 .704193$

Wertheim, A. H. (1981). Occipital alpha activity as a measure of retinal involvement in oculomotor control. Psychophysiology, 18, 432-439. doi: 10.1111/j.14698986.1981.tb02476.x

Wulf, G. (2013). Attentional focus and motor learning: A review of 15 years. International Review of Sport and Exercise Psychology, 6, 77-104. doi: $10.1080 / 1750984 x .2012 .723728$

Zanone, P. G., \& Kelso, J. A. S. (1992). Evolution of behavioural attractors with learning: Nonequilibrium phase transitions. Journal of Experimental Psychology: Human Perception and Performance, 18, 403-421. doi: 10.1037/0096-1523.18.2.403 
Zijlstra, F. R. H. (1993). Efficiency in work behaviour: A design approach for modern tools. Delft: Delft University Press. 
Figures

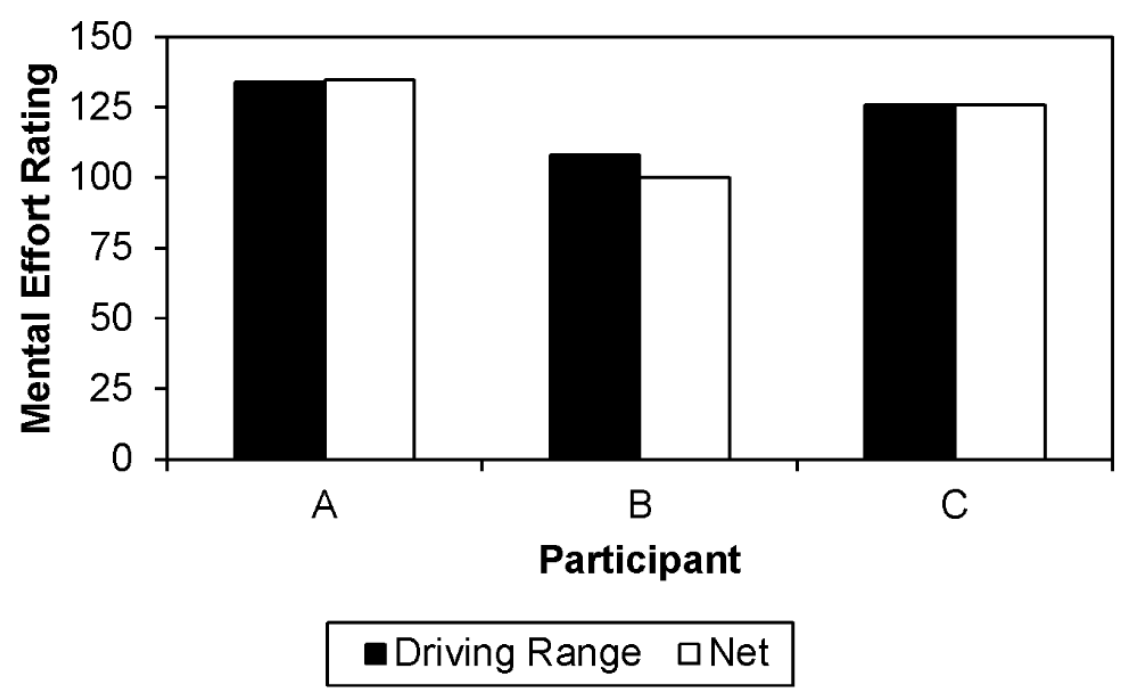

Figure 1. Mental effort ratings for executions in the net and driving range conditions.

Ratings reflect the amount of effort directed towards individual target variables. 
A

\section{Left Elbow Anterior-Posterior Position to Sternum}

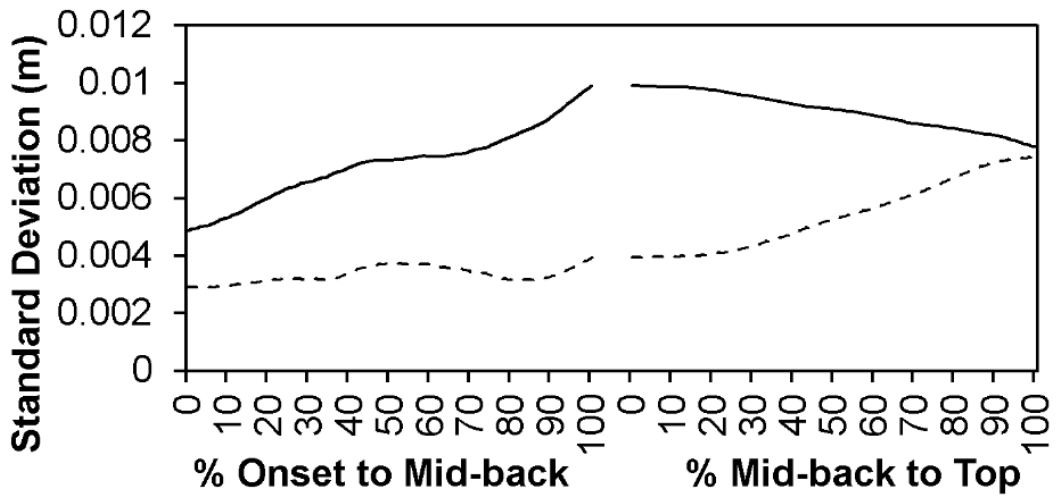

B

Left Hand Anterior-Posterior Position to Right Elbow

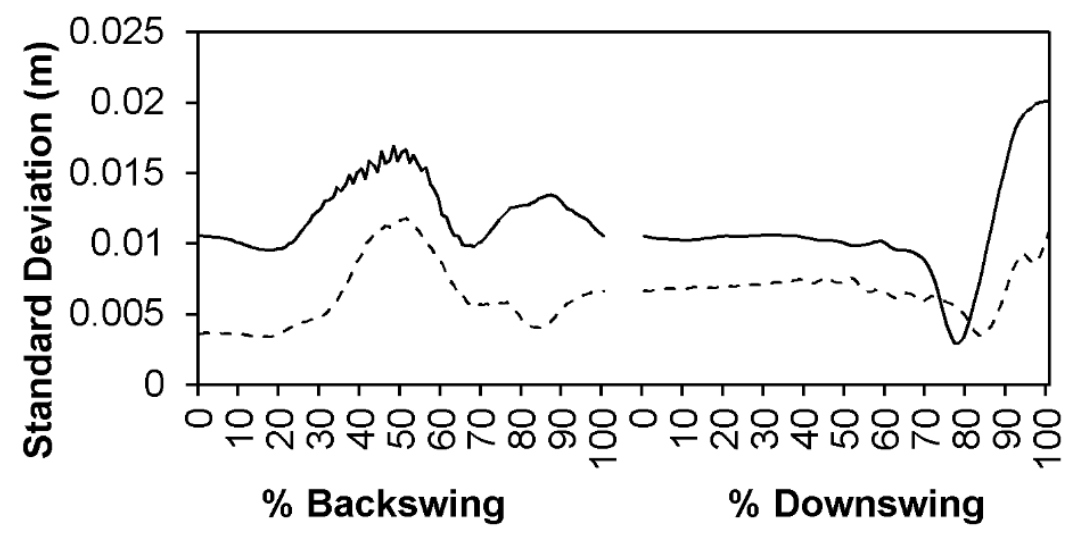

C

Left Shoulder to Pelvis Medial-Lateral Position

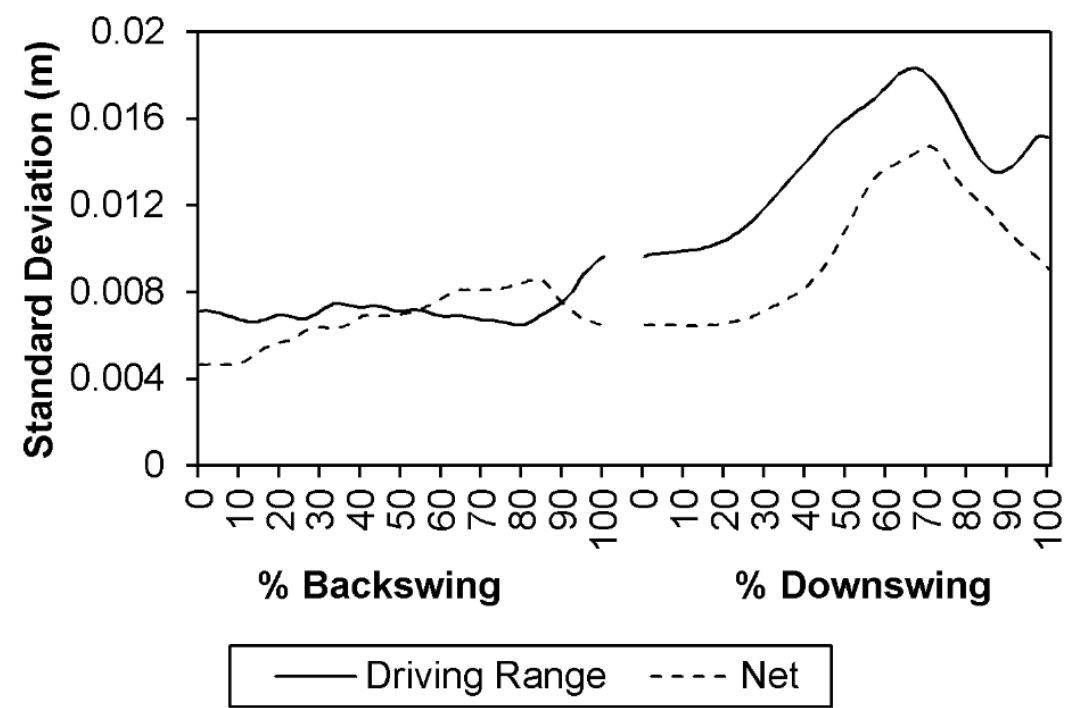

Figure 2. Intra-individual movement variability (as measured by the standard deviation) of participants' target variables at each normalised time frame. 
A

Left Elbow Anterior-Posterior Position to Sternum

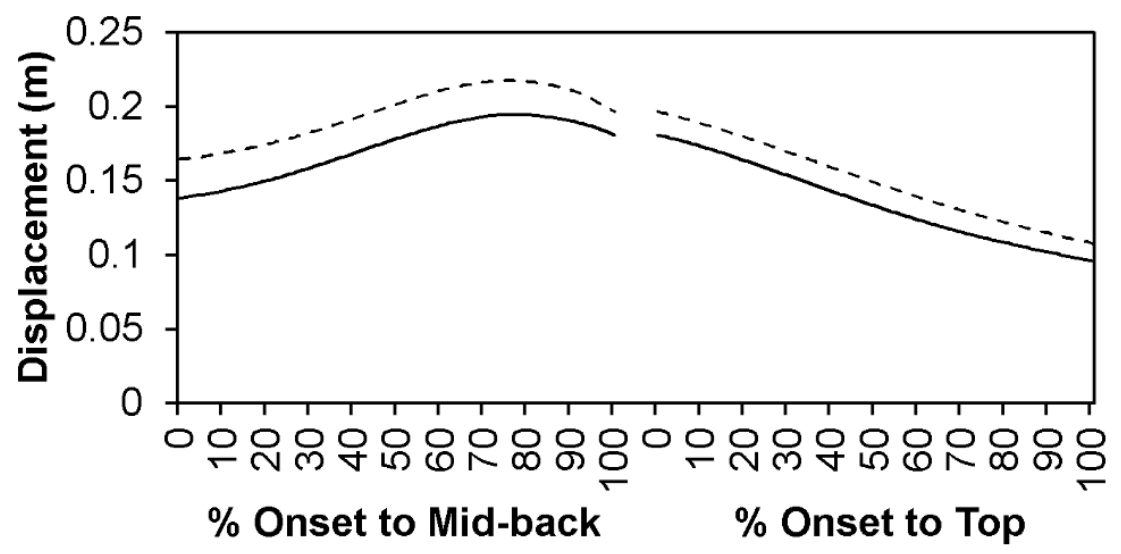

B

Left Hand Anterior-Posterior Position to Right Elbow

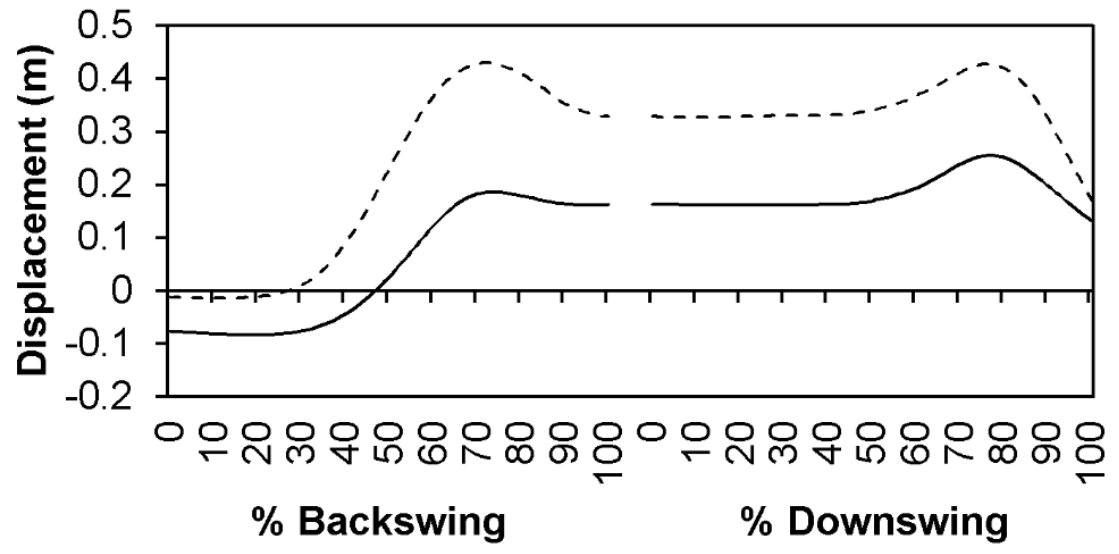

C

Left Shoulder Medial-Lateral Position to Pelvis

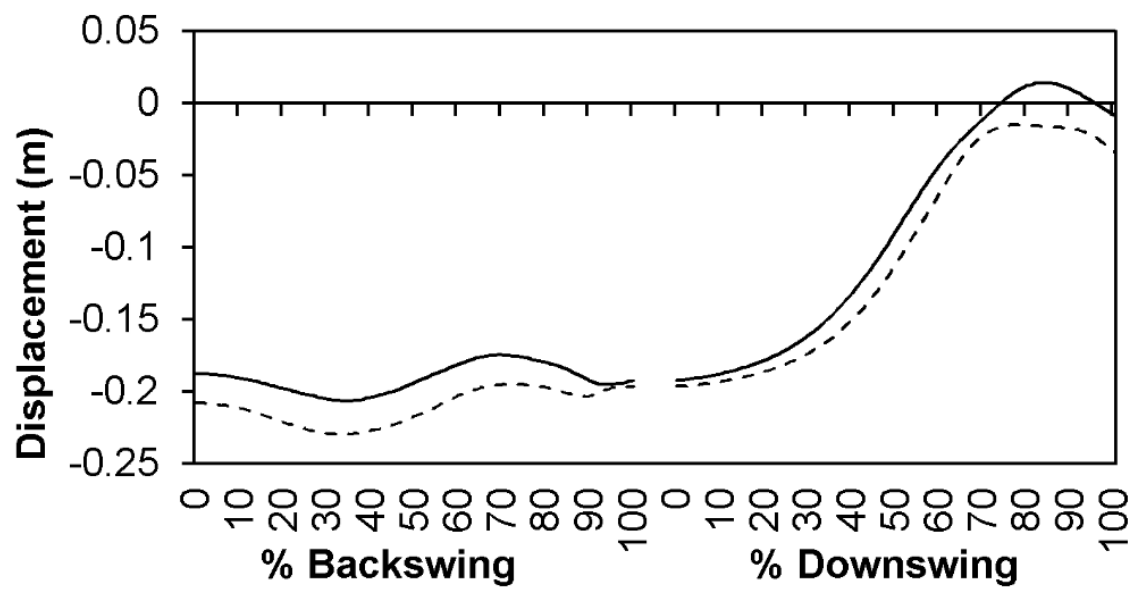

- Driving Range -.-- Net

Figure 3. Kinematics of participants' target variables at each normalised time frame. 